\title{
Variation in Plasma Concentrations of Insulin-Like Growth Factor-I in Pasture-Fed Holstein Cows
}

\author{
F. Y. Obese, ${ }^{*}$ A. R. Rabiee, $\dagger$ K. L. Macmillan, $\dagger^{1}$ A. R. Egan, ${ }^{*}$ S. Humphrys, $\ddagger$ and G. A. Anderson $\dagger$ \\ *School of Agriculture and Food Systems, the University of Melbourne, Victoria 3031, Australia \\ †School of Veterinary Science, the University of Melbourne, Werribee, Victoria 3030, Australia \\ †Primegro Pty. Ltd., Thebarton, SA 5001, Australia
}

\section{ABSTRACT}

The objective of this 5 -wk study was to determine dietary effects on plasma concentrations of insulin-like growth factor-I (IGF-I), as well as milk production and milk components in pasture-fed dairy cows. Thirty-two Holstein cows 4 to 5 wk postpartum were randomly assigned to 4 dietary subgroups. Feed was provided twice daily ad libitum at 0900 and $1600 \mathrm{~h}$ composed of fresh-cut pasture, meadow hay, and pelleted cereal grain to achieve differing levels of DMI and ME density (LL: $16.6 \mathrm{~kg}$ of DMI and $174 \mathrm{MJ}$ of ME; HL: $17.3 \mathrm{~kg}$ of DMI and $181.1 \mathrm{MJ}$ of ME; LH: $15.4 \mathrm{~kg}$ of DMI and 183.1 MJ of ME; HH: $17.9 \mathrm{~kg}$ of DMI and 213.3 MJ of $\mathrm{ME}$, with the first letter indicating DMI and the second $\mathrm{ME}$, and with $\mathrm{H}$ indicating high and $\mathrm{L}$ indicating low, respectively). The first day cows were placed on their diets was designated d 0 . Concentrations of IGF-I were measured in frozen-thawed samples of plasma using a verified ELISA. Dietary treatment had affected plasma concentrations of IGF-I by d 7 with cows on high ME diets having greater IGF-I concentrations at d 14 (83.7 vs. $45.6 \mathrm{ng} / \mathrm{mL}$ ) than cows on the low $\mathrm{ME}$ diets. The level of DMI had less effect on plasma concentrations of IGF-I at d 14 (72.2 vs. $57.1 \mathrm{ng} / \mathrm{mL})$. Dietary treatment effects on these concentrations had stabilized by d 21 . Day-to-day variation in mean plasma concentrations of IGF-I within each dietary treatment was low during an intensive period of daily sampling for $14 \mathrm{~d}$ (from d 22 to 35). Within-cow day-to-day variation was also low compared with that among cows within the same dietary group and was associated with a high repeatability in the day-to-day concentration of IGF-I in individual cows. Intraclass correlation coefficients for IGFI ranged from $0.56( \pm 0.14)$ to $0.88( \pm 0.06)$ with a combined (pooled) value for the 4 subgroups of $0.77( \pm 0.05)$. The ME and DMI effects (H vs. L) at d 35 were 79.3 vs. 41.4 and 62.0 vs. $55.7 \mathrm{ng} / \mathrm{mL}$, respectively. Although

Received August 10, 2007.

Accepted January 13, 2008

${ }^{1}$ Corresponding author: k.macmillan@unimelb.edu.au the ME and DMI differences also affected milk yield and compositional parameters, the effects were not as proportionately great as those measured for IGF-I. Altering the ME or DMI components of the pasture-based diets produced changes in plasma IGF-I concentrations that did not become stabilized for $3 \mathrm{wk}$, but were then highly repeatable for individual cows within each dietary group. Both observations have relevance to interpreting data related to plasma concentrations of IGFI in lactating Holstein cows.

Key words: insulin-like growth factor-I, day-to-day variation, pasture-fed, dairy cow

\section{INTRODUCTION}

Insulin-like growth factor-I is a small peptide of approximately $7 \mathrm{kDa}$ molecular weight that can affect postnatal growth and reproduction (LeRoith et al., 2001). Bioactivity of IGF-I is regulated by binding with high affinity specific insulin-like growth factor binding proteins (IGFBP; Rajaram et al., 1997; Hwa et al., 1999).

Nutrient intake can influence the levels of circulating IGF-I in dairy cattle. High energy intake, protein intake, or both will increase circulating IGF-I concentrations, whereas levels are reduced by lower protein or energy intake (Thissen et al., 1994; Cohick, 1998). Research in North America has established a link between blood IGF-I concentrations in high genetic merit dairy cows fed a TMR under feedlot conditions and changes in energy balance (Lucy et al., 1992; Beam and Butler, 1998). For instance, energy balance was correlated positively with serum concentrations of IGF-I because lactating dairy cows with positive energy balance had higher circulating concentrations of IGF-I than cows in negative energy balance (NEB; Ronge et al., 1988; Spicer et al., 1990; Beam and Butler, 1998). There is no equivalent information on comparable studies in Australian dairy herds where production systems are based mainly on pasture with strategic feeding of grainbased supplements, especially in early lactation. In addition, information on the effect of nutrient status and 
Table 1. Planned differences in DMI and ME for cows in each treatment group ${ }^{1}$

\begin{tabular}{lcc}
\hline $\begin{array}{l}\text { Dietary } \\
\text { subgroup }\end{array}$ & $\begin{array}{c}\text { DM intake } \\
(\mathrm{kg} / \text { cow/d })\end{array}$ & $\begin{array}{c}\text { ME intake } \\
(\mathrm{MJ} / \mathrm{cow} / \mathrm{d})\end{array}$ \\
\hline LL & 16.6 & 174.0 \\
HL & 17.3 & 181.1 \\
LH & 15.4 & 183.1 \\
HH & 17.9 & 213.3 \\
\hline
\end{tabular}

${ }^{1} \mathrm{H}=$ high and $\mathrm{L}=$ low, where the first letter denotes DMI and the second denotes ME.

energy balance on circulating IGF-I levels has been based mainly on data from the weekly blood sampling of cows fed TMR diets. Data on day-to-day variation in concentrations of IGF-I in blood plasma are limited.

The present study used a commercial IGF-I ELISA kit (Diagnostic Systems Laboratories Inc., Webster, TX; Obese et al., 2008) to test the hypothesis that diets composed of 2 levels of DMI and ME density could affect plasma concentrations of IGF-I. The day-to-day variation in concentrations of IGF-I and individual cow variability in lactating Holstein cows fed pasture during early lactation were also assessed.

\section{MATERIALS AND METHODS}

\section{Animals and Experimental Design}

The experiment was conducted at the Department of Primary Industry's Ellinbank Dairy Research Institute (38.27 S lat; $145.56 \mathrm{~W}$ long) between August and September, 2000. It received approval from the Ethics Committee of the Department of Primary Industries, Ellinbank. Lactating Holstein cows $(n=32)$ in their second or subsequent lactations and from 4 to $5 \mathrm{wk}$ postpartum (initial mean live weight of $504.8 \pm 10.0 \mathrm{~kg}$; SEM; range 411 to $621 \mathrm{~kg}$ ) were treated with an implant of a $6 \mathrm{mg}$ of GnRH-agonist (Deslorelin, Peptech Animal Health, Sydney, Australia), followed by 2 injections of $\mathrm{PGF}_{2 \alpha}$ (2 mL of Prosolvin, Intervet, Melbourne, Australia) at 0800 and $1600 \mathrm{~h} 10 \mathrm{~d}$ later. This treatment prevented cows from cycling and producing progesterone as part of a concurrent study to measure the effects of DMI and ME density on metabolic clearance rates of administered progesterone (Rabiee et al., 2001).

The cows were randomly assigned to 4 treatment groups in a $2 \times 2$ factorial design after matching on parity, current milk production, and calving date. Feed was provided twice daily at 0900 and $1600 \mathrm{~h}$ composed of fresh-cut pasture, meadow hay, and pelleted cereal grain to achieve differing levels of DMI and ME density (Table 1). The study period was for $5 \mathrm{wk}$ composed of a 3-wk adaptation period (designated as the transition phase) followed by $2 \mathrm{wk}$ of intensive sampling (desig- nated as the stable phase). The first day cows received their allocated diet was designated $d 0$. Cows were first fed with pelleted cereal grain at $0900 \mathrm{~h}$, followed by pasture in the high ME (HME) groups ( $\mathrm{LH}$ and $\mathrm{HH}$ subgroups), or hay and then pasture in the low ME groups (LL and HL subgroups). They were fed indoors in individual stanchions and were individually offered their diets for $5 \mathrm{~h}$ after each milking at 0600 and 1500 $h$. They were then held as a single group in a bare yard after each feeding period but had access to water. Feed allowances were weighed out as well as refusals for grass, hay, and grain so that intakes were measured daily.

\section{Feed Processing and Analysis}

Pasture was cut to approximately $40 \mathrm{~mm}$ twice daily and harvested using a loader wagon. The DM content of pasture was estimated using a microwave (high for $9 \mathrm{~min}$ ) so that the correct amount of fresh pasture could be calculated for each cow. A representative sample of each of the feeds offered and refused was dried at $105^{\circ} \mathrm{C}$ to constant weight to determine the actual DM content. An additional subsample of all feeds offered was bulked on a weekly basis and dried at $65^{\circ} \mathrm{C}$ for $72 \mathrm{~h}$, ground, and analyzed for in vitro DM digestibility (DMD) and $\mathrm{N}$. The DMD was estimated by the method of Clarke et al. (1982). The ME was calculated from DMD $\{[\mathrm{ME}=$ $(\mathrm{DMD} \times 0.17)-2]\}(\mathrm{SCE}, 1990)$. The nitrogen content was measured by the Kjeldahl method. The CP was calculated from the nitrogen data $(\mathrm{CP}=\mathrm{N} \times 6.25)$. The DMD, ME, and protein content of the various feeds offered are presented in Table 2 . The diet composition and actual differences in DM intake of pasture, hay, and pellets and average DM, DMD, ME, and CP of the experimental diets are shown in Table 3.

\section{Blood Sampling Protocol}

Blood sampling was by venipuncture from a coccygeal vein into $10 \mathrm{~mL}$ of heparinized Vacutainer tubes occurring once weekly at $0700 \mathrm{~h}$ after the morning milking on d $0,7,21,28$, and 35 . Additional samples were collected daily from d 22 to 35 at $0700 \mathrm{~h}$ to provide comparative estimates of day-to-day variation during the stable phase of the study. Each blood sample was placed initially on ice and then centrifuged $(1,600 \times g$ for 15 min at $4^{\circ} \mathrm{C}$ ) within $10 \mathrm{~min}$ of collection. Plasma was aspirated and stored at $-20^{\circ} \mathrm{C}$ until assayed for IGF-I.

\section{Plasma IGF-I Assay}

Plasma IGF-I concentrations were measured using a validated DSL-10-2800 Active Nonextraction IGF-I 
Table 2. Chemical analysis of the various feed types in the rations

\begin{tabular}{lcccc}
\hline Item & $\begin{array}{c}\text { Digestibility } \\
(\%)\end{array}$ & $\mathrm{DM}(\%)$ & $\mathrm{CP}(\%)$ & $\mathrm{ME}(\mathrm{MJ})$ \\
\hline Low energy pellet & 75.3 & 96.8 & 16.7 & 11.3 \\
High energy pellet & 86.4 & 96.5 & 12.9 & 13.3 \\
Pasture (ryegrass and clover) & 77.5 & 15.4 & 23.8 & 11.2 \\
Hay & 64.6 & 82.4 & 14.1 & 9.0 \\
\hline
\end{tabular}

ELISA kit (DSL Inc., Webster, TX). The ELISA was validated against an IGF-I RIA in which IGF-I in plasma samples have been dissociated and extracted from IGFBP by size exclusion chromatography under acid conditions (Obese et al., 2008). The intraassay and interassay coefficients of variation of the IGF-I ELISA for plasma were 2.27 and $4.11 \%$, respectively.

\section{Milk Yield and Milk Components}

Milk yield was recorded at every morning and evening milking for the $5 \mathrm{wk}$ using a standard herd recording device. A sample of whole milk was preserved with $0.5 \%$ bromopol and refrigerated at $4^{\circ} \mathrm{C}$ for compositional analyses (milk lactose, total protein, and total fat) at weekly intervals using a MilkoScan (Foss Electric, Hillerød, Denmark). These compositional data were used to calculate yields for lactose, protein, and fat.

\section{Statistical Analyses}

The effects of DMI and ME on plasma concentrations of IGF-I, milk yield, and milk components, and interaction between DMI and ME density at $\mathrm{d} 14$ of the transition phase and $d 35$ of the stable phase were analyzed using the GLM procedure in SPSS v. 11.5 (SPSS, 2002). Data for $\mathrm{d} 0$ were obtained before cows had access to their various diets, and these data were used as covariates. The model used was

Table 3. Actual differences in DMI of pasture, hay, and pellets and average DM, DM digestibility (DMD), $\mathrm{ME}$, and CP content of the experimental $\operatorname{diets}^{1}$

\begin{tabular}{lcccc}
\hline DMI (kg/cow/d) & HL & LL & LH & HH \\
\hline Pasture & 6.3 & 6.1 & 10.4 & 11.0 \\
Hay & 4.9 & 4.3 & - & - \\
Low energy pellet & 6.2 & 6.1 & - & - \\
High energy pellet & - & - & 4.9 & 6.8 \\
Diet composition & & & & \\
DM (\%) & 32.5 & 21.9 & 21.2 & 22.8 \\
DMD (g/kg of DM) & 73.5 & 72.8 & 79.8 & 80.4 \\
ME (MJ of ME/kg of DM) & 10.4 & 10.5 & 11.9 & 11.9 \\
CP (g/kg of DM) & 18.6 & 18.4 & 20.2 & 19.5 \\
\hline
\end{tabular}

${ }^{1} \mathrm{H}=$ high and $\mathrm{L}=$ low, where the first letter denotes DMI and the second denotes ME.

$$
\mathrm{Y}=\mathrm{DMI}+\mathrm{ME}+\mathrm{DMI} \times \mathrm{ME}+\text { covariate at } \mathrm{d} 0,
$$

where $\mathrm{Y}=$ variable at $\mathrm{d} 14$ or 35 . The interaction term was included in the model if its probability was $<0.1$. Intraclass correlations (Snedecor and Cochran, 1980) were used to assess the day-to-day variation in plasma concentrations of IGF-I of cows within each group during the $14 \mathrm{~d}$ of the stable phase. Calculation of the intraclass correlation coefficient (ICC) of each treatment group used the loneway command software (StataCorp, 2001) in which:

$$
\mathrm{ICC}=\frac{\sigma^{2} \text { cow }}{\sigma^{2} \operatorname{cow}+\sigma^{2} \mathrm{e}}
$$

where ICC is equal to the proportion of the total variance that is due to the between cow variance, and $\sigma^{2} \mathrm{e}$ is the error variance. In addition, the Kendall's coefficient of concordance was calculated as a measure of the agreement among rankings of the cows over each of the $14 \mathrm{~d}$ of the stable phase for plasma IGF-I measurements (Kendall,1962).

\section{RESULTS}

\section{Changes in Plasma Concentration of IGF-I During the Transition and Stable Phases}

Dietary treatments had influenced IGF-I concentrations for each group by d 7 with individual trends continuing to $d 21$. The changes in IGF-I reflected ME density to a greater degree than DMI (Figure 1). The mean plasma concentrations of IGF-I were highest in cows on the HME diets (LH and HH subgroups) at d $14(P<0.001)$ in the transition phase and d $35(P<$ $0.001)$ in the stable phase compared with cows on the low ME diets (LL and HL subgroups). The DMI treatment had less influence on the mean plasma concentrations of IGF-I at d $14(P=0.057)$ and d $35(P=0.083)$. The DMI $\times$ ME interaction for IGF-I concentration was significant at d $14(P<0.047)$ in the transition phase because of a spike in concentrations of IGF-I among cows in the HH subgroup. The interaction between DMI and ME was not statistically significant at d $35(P=$ $0.61)$. 


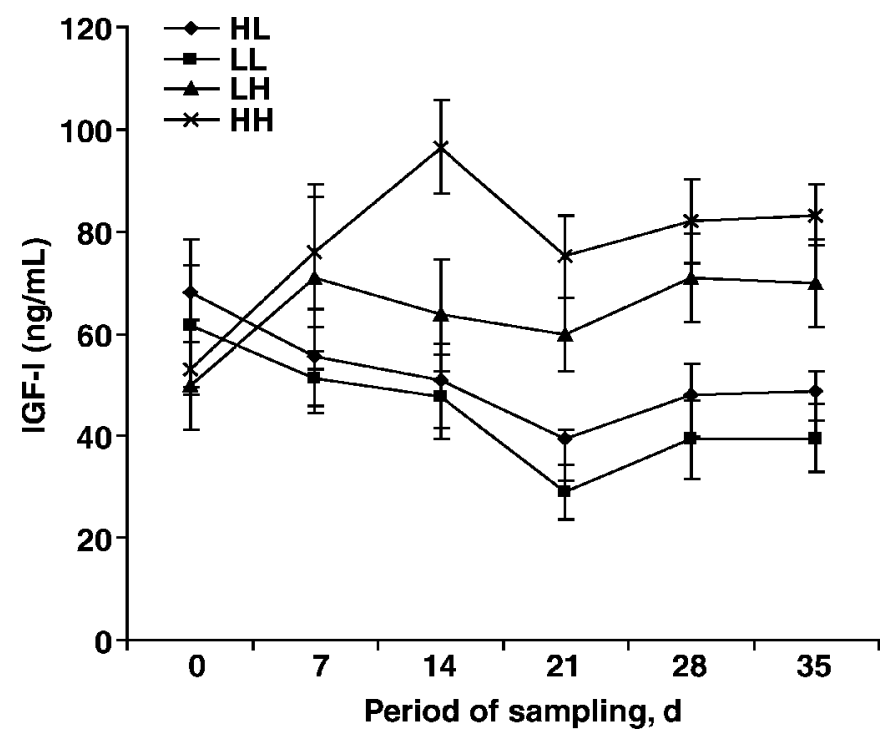

Figure 1. Changes in plasma concentrations of IGF-I (mean \pm SE) for 32 cows fed 4 diets ( $\mathrm{n}=8$ cows per dietary treatment; $\mathrm{HH}=$ high DMI and high ME; HL = high DMI and low ME; LH = low DMI and high ME; LL = low DMI and low ME).

\section{Daily Variation in Plasma Concentrations of IGF-I}

The plasma concentrations of IGF-I measured during the 14 consecutive days of sampling in the stable phase showed that levels remained relatively constant for each of the 4 dietary groups (Figure 2). Day-to-day variation within individual cows was less compared with that among cows within the same dietary group. Cows exhibited consistently high, medium, or low plasma concentrations of IGF-I relative to the group mean. Examples of this level of repeatability for cows having the highest and the lowest plasma concentrations of IGF$\mathrm{I}$ in the HH and LL groups are shown in Figure 3. The ICC as a measure of the proportion of the total variance that was due to between-cow variance were $0.56 \pm 0.14$, $0.75 \pm 0.11,0.81 \pm 0.09$, and $0.88 \pm 0.06$ for the subgroups $\mathrm{HL}, \mathrm{HH}, \mathrm{LH}$, and LL, respectively, and was $0.77 \pm 0.05$ for the 4 groups combined (pooled ICC), based on the deviations from each group mean. Similarly, there was a high level of agreement among rankings of cows within a group over each of the $14 \mathrm{~d}$ of plasma IGF-I measurement as indicated by Kendall's coefficients of concordance $(\mathrm{HL}=0.65 ; \mathrm{HH}=0.78 ; \mathrm{LH}=0.86 ; \mathrm{LL}=$ 0.93 ; each $P<0.001$ ), and 0.84 for the combined groups

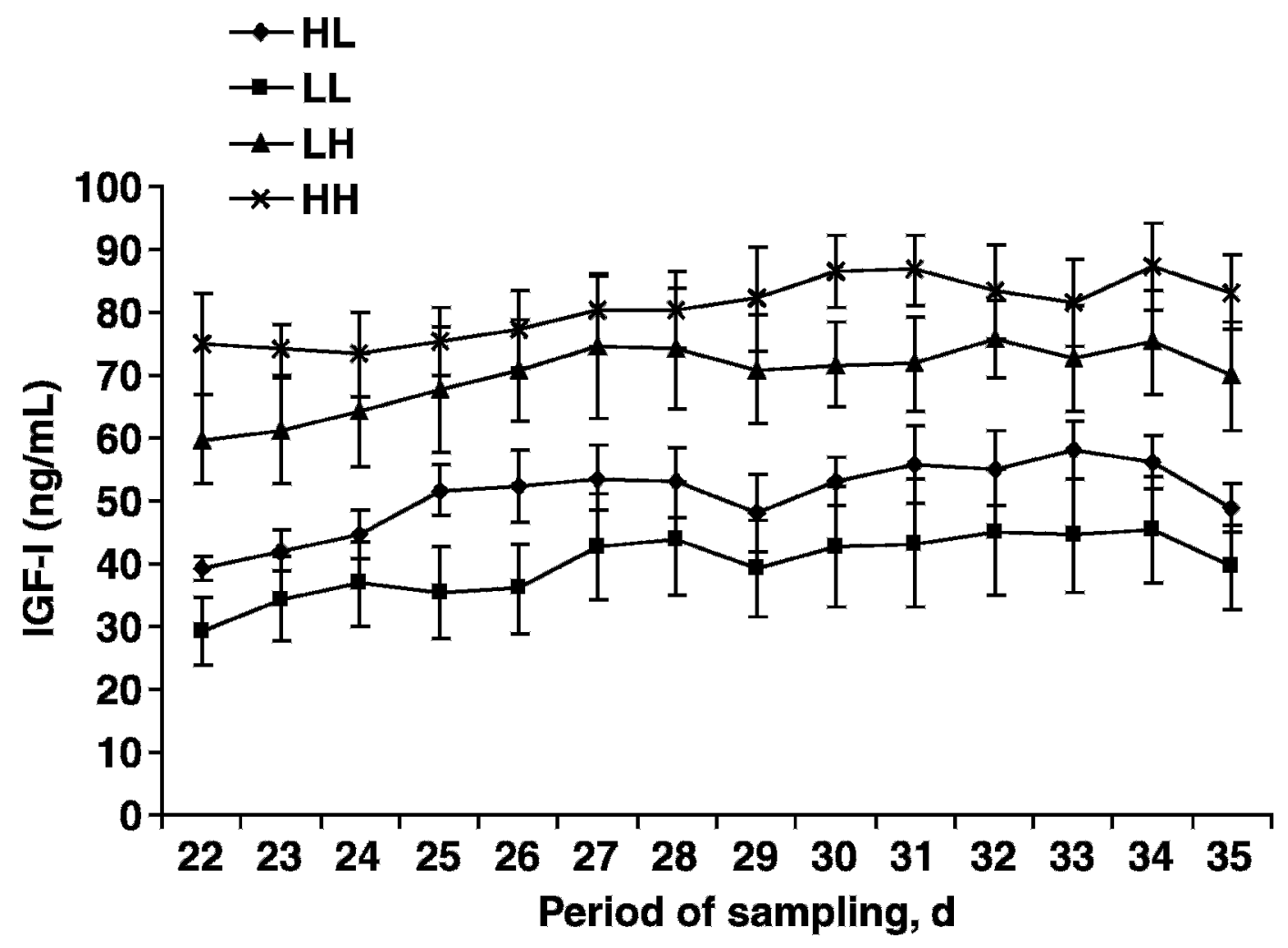

Figure 2. Daily plasma concentrations of IGF-I (mean \pm SE) in 32 cows fed 4 diets $(n=8$ cows per dietary treatment; HH $=$ high DMI and high ME; HL = high DMI and low ME; LH = low DMI and high ME; LL = low DMI and low ME). 


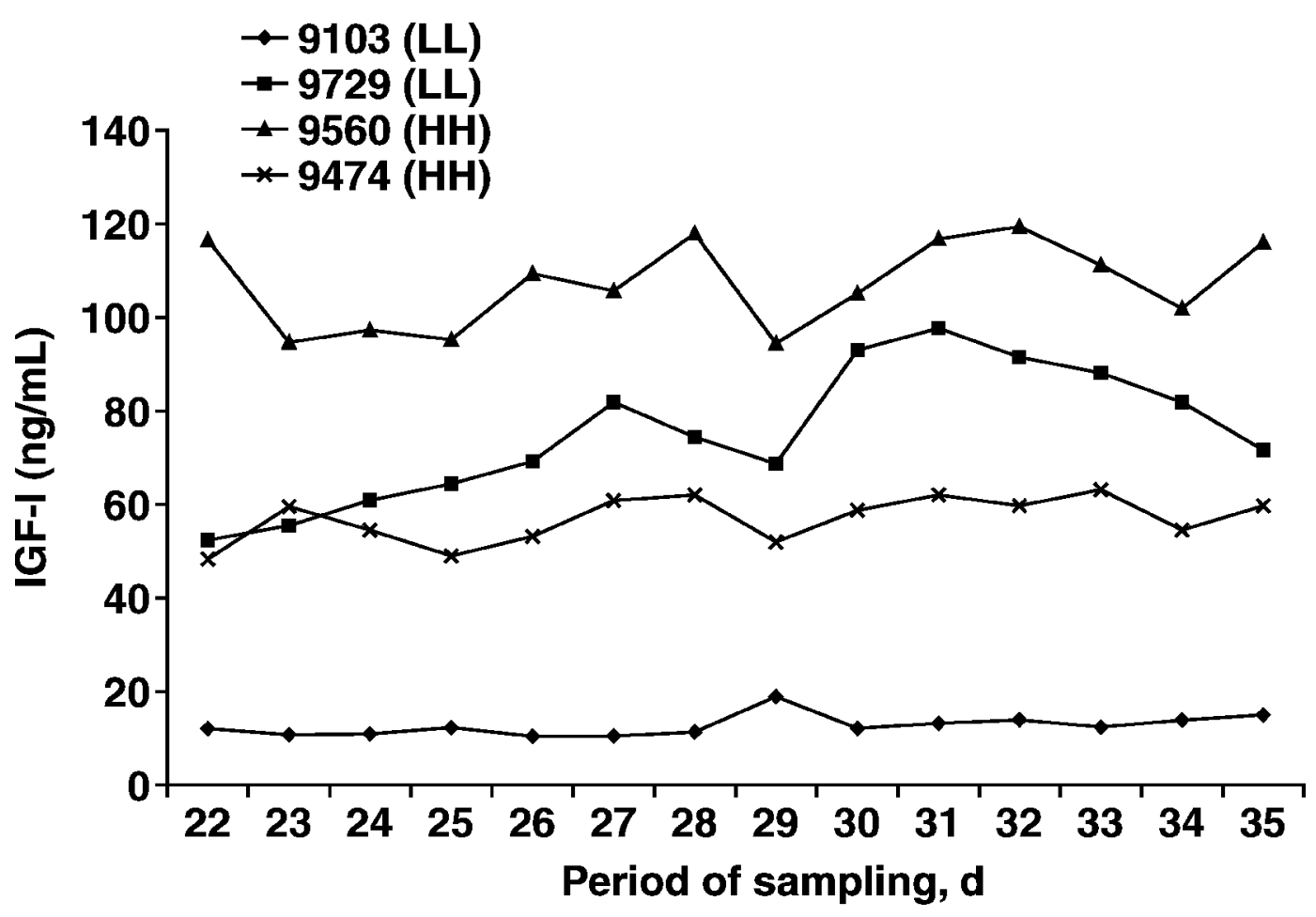

Figure 3. Plasma IGF-I profiles of individual cows with the highest and lowest plasma concentrations of IGF-I within the dietary subgroups with high DMI and high ME (HH), and low DMI and low ME (LL).

(pooled over all groups and using the deviations from the group means).

\section{Milk Yield and Milk Composition During the Transition and Stable Phases}

Dietary treatment influenced mean milk yield during the 5-wk study. Cows in the HH group had the highest milk production, while those in the LL group had the lowest (Figure 4). The mean daily milk yield at $\mathrm{d} 0$ was $28.9 \mathrm{l}$, ranging from $27.8 \mathrm{l}$ for the $\mathrm{LH}$ group to $30 \mathrm{~L}$ for the HL group $(P>0.05)$. There was no correlation between cow yield and IGF-I concentrations across dietary treatment $(\mathrm{r}=0.058, P=0.754)$. Overall means for daily yields of lactose, milk fat, and protein were $1.34 \pm 0.04,1.29 \pm 0.04$, and $0.82 \pm 0.02 \mathrm{~kg} / \mathrm{cow}$. Mean composition statistics were $4.99 \pm 0.03,4.85 \pm 0.12$, and $3.04 \pm 0.03 \%$ for lactose, fat, and protein. Daily milk yields at d 35 were affected by DMI and ME concentration $(P<0.001$; Table 4$)$. The interaction between these 2 dietary components was also significant $(P<0.001$; Table 4); the effect of the high ME density was only apparent with the higher DMI. Similar interactive effects of diet were also observed with daily yields of lactose and protein at d $35(P<0.001)$, but not with milk fat. Statistically significant milk compositional effects at d 35 only involved increases in lactose and protein concentrations for the diets with the higher ME density $(P<0.001$; Table 5$)$.

\section{DISCUSSION}

The results from this study have demonstrated that changes in diets based on fresh pasture resulted in

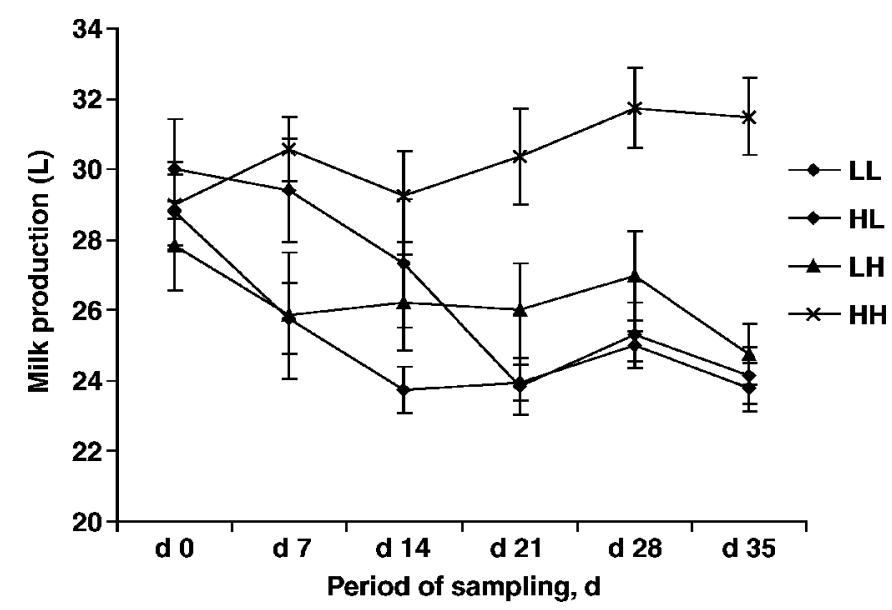

Figure 4. Daily milk production (mean \pm SE) in 32 cows fed 4 $\operatorname{diets}(\mathrm{n}=8$ cows per dietary treatment; $\mathrm{HH}=$ high DMI and high $\mathrm{ME} ; \mathrm{HL}=$ high DMI and low ME; LH = low DMI and high ME; LL = low DMI and low ME). 
Table 4. Unadjusted subgroup means, least squares (LS) means, and probability values for milk yield at d 14 and $35^{1}$

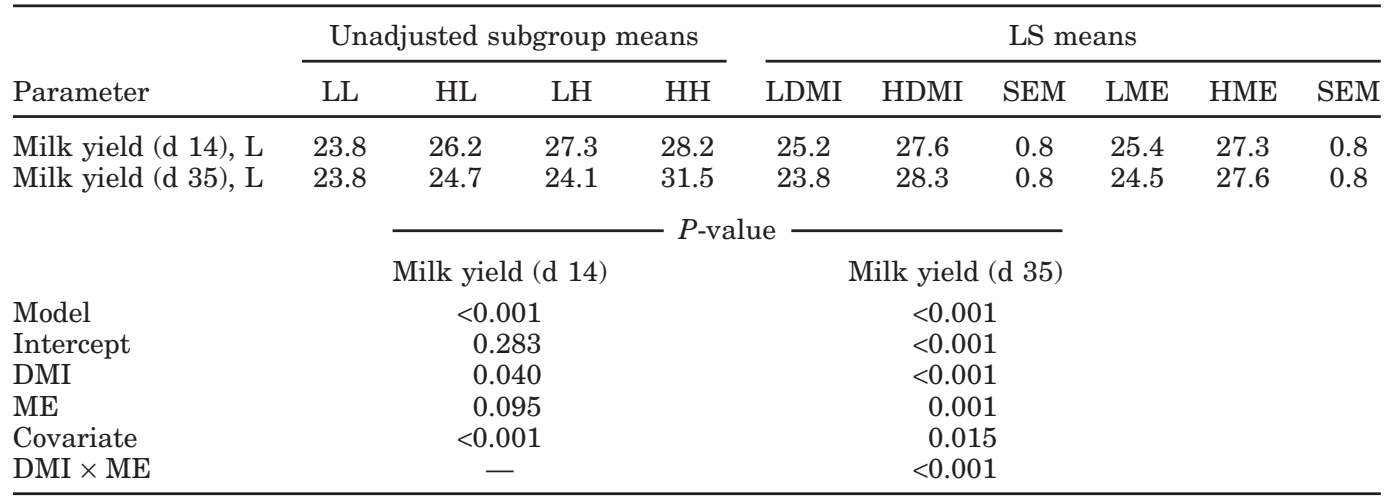

${ }^{1} \mathrm{LDMI}=$ low DMI; HDMI = high DMI; LME = low ME; HME = high ME; LL = low DMI and low ME; $\mathrm{HL}=$ high DMI and low ME; LH = low DMI and high ME; HH = high DMI and high ME.

changes in plasma concentrations that were occurring by $\mathrm{d} 7$ but continued for a further 2 wk (to $\mathrm{d} 21$ ) before stabilizing at 4 different levels. The ME density of the diet affected circulating IGF-I concentrations to a greater degree than DMI. Cows receiving the HME rations ( $\mathrm{HH}$ and $\mathrm{LH}$; Figure 1) increased their average plasma IGF-I concentrations from d 0 to 21 and maintained these higher concentrations from d 22 to 35 (Figure 2). The interaction between DMI and ME density at d 14 may have reflected the greater impact of a high ME diet when combined with higher DM intake. The ME density effect is consistent with other studies indicating higher plasma concentrations of IGF-I in dairy cows (Lucy et al., 1992; Andersen et al., 2004) and heifers (Armstrong et al., 2001) offered high energy diets.

The average IGF-I concentrations for the 4 diets ranged from 29.1 to $96.4 \mathrm{ng} / \mathrm{mL}$ (Figure 1). Since the influence of diet was so profound, comparisons with other studies involving different diets not based on pasture are limited. Nonetheless, comparable ranges of 25 to $76 \mathrm{ng} / \mathrm{mL}, 44$ to $92.8 \mathrm{ng} / \mathrm{mL}$, and 40 to $75 \mathrm{ng} / \mathrm{mL}$ have been reported for Holstein cows on TMR by Vega et al.
(1991), Abribat et al. (1990), and Spicer et al. (1993), respectively. The concentrations on the pasture-based diets used in the present study were lower than those reported by Snijders et al. (2001) for Holstein cows of high genetic merit ( 120 to $130 \mathrm{ng} / \mathrm{mL}$ ) or average genetic merit (130 to $150 \mathrm{ng} / \mathrm{mL}$ ).

The repeatability in average plasma concentrations of IGF-I for each group during the intensive sampling from d 22 to 35 was high (Figure 2). The levels in individual cows remained relatively constant and did not fluctuate appreciably from day to day, with cows having either consistently high, medium, or low IGF-I concentrations relative to their group means (Figure 3). The ICC of $0.77 \pm 0.05$ and a Kendall's coefficient of concordance of 0.84 over the 4 groups were indicative of a marked cow component in the variation in IGF-I concentrations. This high repeatability with respect to dayto-day variation in plasma concentrations of IGF-I in individual Holstein cows may be genetically influenced. Its heritability in young dairy cattle was estimated as 0.35 (Grochowska et al., 2001), with values ranging from 0.31 to 0.59 reported in beef cattle (Davis and

Table 5. Unadjusted subgroup means, least squares (LS) means and probability values for milk components at $\mathrm{d} 35^{1}$

\begin{tabular}{|c|c|c|c|c|c|c|c|c|c|c|c|c|}
\hline \multirow[b]{2}{*}{ Parameter } & \multicolumn{4}{|c|}{ Unadjusted subgroups means } & \multicolumn{7}{|c|}{ LS means } & \multirow[b]{2}{*}{$P$-value } \\
\hline & LL & $\mathrm{HL}$ & $\mathrm{LH}$ & $\mathrm{HH}$ & LDMI & HDMI & SEM & SIG & LME & HME & SEM & \\
\hline Lactose (\%) & 4.88 & 4.94 & 4.94 & 5.03 & 4.96 & 4.93 & 0.03 & NS & 4.84 & 5.03 & 0.03 & $* * *$ \\
\hline Lactose yield $(\mathrm{kg})$ & 1.18 & 1.22 & 1.19 & 1.58 & 1.17 & 1.40 & 0.04 & $* * *$ & 1.20 & 1.38 & 0.04 & $* * *$ \\
\hline Protein $(\%)$ & 2.90 & 2.96 & 3.13 & 3.21 & 3.05 & 3.05 & 0.03 & NS & 2.92 & 3.18 & 0.03 & $* * *$ \\
\hline Protein yield $(\mathrm{kg})$ & 0.70 & 0.73 & 0.75 & 1.01 & 0.72 & 0.87 & 0.02 & $* * *$ & 0.72 & 0.88 & 0.02 & $* * *$ \\
\hline Fat $(\%)$ & 5.15 & 5.16 & 4.99 & 4.41 & 5.04 & 4.82 & 0.22 & NS & 5.01 & 4.85 & 0.23 & $* *$ \\
\hline Fat yield (kg) & 1.23 & 1.28 & 1.20 & 1.39 & 1.22 & 1.33 & 0.07 & NS & 1.25 & 1.30 & 0.07 & NS \\
\hline
\end{tabular}

${ }^{1} \mathrm{LDMI}$ = low DMI; HDMI = high DMI; LME = low ME; HME = high ME; LL = low DMI and low ME; $\mathrm{HL}=$ high DMI and low ME; LH = low DMI and high ME; HH = high DMI and high ME.

$* * P<0.01 ; * * * P<0.001$. 
Simmen, 1997, 2000; Johnston et al., 2001; Yilmaz et al., 2004). Another possible reason for the low fluctuation in IGF-I concentrations within individual cows may relate to the relatively long half-life of IGF-I in the blood as a result of binding with specific IGFBP in the blood (Zapf et al., 1986; Comin et al., 2002). Because daily plasma concentrations of IGF-I for individual cows were similar to those for weekly samples for the same cow, animals should be able to be sampled at weekly intervals to ascertain any changes in IGF-I concentrations provided they remain on the same diet. If dietary intake or composition is altered, then plasma concentrations of IGF-I may continue to change for at least 3 wk (as shown in Figure 1).

The average daily yields of milk throughout the trial were similar to those reported for Holstein cows in commercial herds in the Ellinbank region that had seasonally concentrated calving patterns and received pasture-based diets supplemented with some grain (Auldist et al., 2007). Only the cows receiving the $\mathrm{HH}$ diet increased daily milk yields over the $35 \mathrm{~d}$, but the change was from 29 to $31 \mathrm{~L}$. The level of DMI as well as dietary ME density both affected yields of milk (Table 4), lactose, and protein at d 35 and involved a significant interaction (Table 5). These effects clearly differed from the dietary effects observed on plasma concentrations of IGF-I.

\section{CONCLUSIONS}

The plasma concentrations of IGF-I in cows reflected diet composition and nutritional status with daily intakes of ME having a greater effect on plasma IGF-I concentrations than DMI. The changes in these concentrations were apparent within $7 \mathrm{~d}$ of introducing each diet, but separate trends continued for a further $14 \mathrm{~d}$. Thereafter, average daily concentrations for each dietary group became stabilized. Interanimal variation in plasma concentrations of IGF-I was higher than withinanimal variation in each of the dietary groups from $d$ 22 to 35 of the stable phase. The study has demonstrated that IGF-I concentrations remain fairly constant and do not change appreciably between days in individual cows fed pasture-based diets as long as they remain on a constant diet. The initial slow rate of change combined with the eventual limited amount of variation for individual animals should have implications for experimental designs in studies investigating the effect of nutritional status or energy balance on changes in plasma concentrations of IGF-I. Results from this study suggest that changes in plasma concentrations of IGF-I for individual cows over a designated period of time may be more important than simply comparing group means, especially when diets may differ.

\section{ACKNOWLEDGMENTS}

Appreciation is expressed to the University of Melbourne, Dairy Australia, Primegro Ltd. (Adelaide) and the Cooperative Research Centre for Tissue Growth and Repair (Adelaide) for supporting the project.

\section{REFERENCES}

Abribat, T., H. Lapierre, P. Dubreuil, G. Pelletier, P. Gaudreau, P. Brazeau, and D. Petitclerc. 1990. Insulin-like growth factor-I concentration in Holstein Female cattle: Variations with age, stage of lactation and growth hormone-releasing factor administration. Domest. Anim. Endocrinol. 7:93-102.

Andersen, J. B., N. C. Friggens, T. Larsen, M. Vestergaard, and K. L. Ingvartsen. 2004. Effect of energy density in the diet and milking frequency on plasma metabolites and hormones in early lactation dairy cows. J. Vet. Med. A 51:52-57.

Armstrong, D. G., T. G. McEvoy, G. Baxter, J. J. Robinson, C. O. Hogg, K. L. Woad, R. Webb, and K. D. Sinclair. 2001. Effect of dietary energy and protein on bovine follicular dynamics and embryo production in vitro: Associations with the ovarian insulinlike growth factor system. Biol. Reprod. 64:1624-1632.

Auldist, M. J., M. F. S. Pyman, C. Grainger, and K. L. Macmillan. 2007. Comparative reproductive performance and early lactation productivity of Jersey $\times$ Holstein cows in predominantly Holstein herds in a pasture-based dairying system. J. Dairy Sci. 90:4856-4862.

Beam, S. W., and W. R. Butler. 1998. Energy balance, metabolic hormones, and early postpartum development in dairy cows fed prilled lipid. J. Dairy Sci. 81:121-131.

Clarke, T., P. C. Flinn, and A. A. McGowan. 1982. Low cost pepsincellulase assays for the prediction of digestibility of herbage. Grass Forage Sci. 37:147-150.

Cohick, W. S. 1998. Role of the insulin-like growth factors and their binding proteins in lactation. J. Dairy Sci. 81:1769-1777.

Comin, A., D. Gerin, A. Cappa, V. Marchi, R. Renaville, M. Motta, U. Faazzini, and A. Prandi. 2002. The effect of an acute energy deficit on the hormone profile of dominant follicles in dairy cows. Theriogenology 58:899-910.

Davis, M. E., and R. C. M. Simmen. 1997. Genetic parameter estimates for serum insulin-like growth factor-I concentration and performance traits in Angus beef cattle. J. Anim. Sci. 75:317-324.

Davis, M. E., and R. C. M. Simmen. 2000. Genetic parameter estimates for serum insulin-like growth factor-I concentration and carcass traits in Angus beef cattle. J. Anim. Sci. 78:2305-2313.

Grochowska, R., P. Sorensen, L. Zwierzchowski, M. Snochowski, and P. Lovendahl. 2001. Genetic variations in stimulated GH release and in IGF-I of young dairy cattle and their associations with the leucine/valine polymorphism in GH gene. J. Anim. Sci. 79:450-476.

Hwa, V., Y. Oh, and R. G. Rosenfeld. 1999. The insulin-like growth factor-binding protein (IGFBP) superfamily. Endocr. Rev. 20:761-787.

Johnston, D. J., R. Herd, A. Reverter, and V. H. Oddy. 2001. Heritability of IGF-I in beef cattle and its association with growth and carcass traits. Pages 164-166 in Proc. 14th Assoc. Advmt. Anim. Breed. Genet., Queenstown, New Zealand. Assoc. Advmt. Anim. Breed. Genet., Armidale, NSW, Australia.

Kendall, M. G. 1962. Rank Correlation Methods. 3rd ed. Charles Griffin, London, UK.

LeRoith, D., C. Bondy, S. Yakar, J. L. Liu, and A. Butler. 2001. The Somatomedin hypothesis. Endocr. Rev. 22:53-74.

Lucy, M. C., J. Beck, C. R. Staples, H. H. Head, R. L. de la Sota, and W. W. Thatcher. 1992. Follicular dynamics, plasma metabolites, hormones and insulin-like growth factor I (IGF-I) in lactating cows with positive or negative energy balance during the preovulatory period. Reprod. Nutr. Dev. 32:331-341.

Obese, F. Y., S. Humphrys, K. L. Macmillan, and A. R. Egan. 2008. Measuring concentrations of insulin-like growth factor-I with an 
enzyme-linked immunosorbent assay in plasma samples from Holstein cows. J. Dairy Sci. 91:160-168.

Rabiee, A. R., K. L. Macmillan, F. Schwarzenberger, D. Thaller, M. J. Rathbone, and T. E. Trigg. 2001. Suppression of ovarian steroidogenesis in dairy cows using deslorelin implant for the purpose of evaluating progesterone metabolism. Aust. Vet. J. 79:690-694.

Rajaram, S., D. J. Baylink, and S. Mohan. 1997. Insulin-like growth factor binding proteins in serum and other biological fluids: Regulation and functions. Endocr. Rev. 18:801-831.

Ronge, H., J. W. Blum, C. Clemment, F. Jans, H. Leuenbeger, and H. Binder. 1988. Somatomedin C in dairy cows related to energy and protein supply and to milk production. Anim. Prod. 47:165-183.

SCA. 1990. Feeding standards for Australian livestock. Ruminants. Standing Committee on Agriculture (SCA), CSIRO Publishing, Melbourne, Australia.

Snedecor, G. W., and W. G. Cochran. 1980. Statistical Methods. 7th ed. Iowa State University Press, Ames, IA.

Snijders, S. E. M., P. G. Dillon, K. J. O’Farrell, M. G. Diskin, A. R. G. Wylie, D. O'Callaghan, M. Rath, and M. P. Boland. 2001. Genetic merit for milk production and reproductive success in dairy cows. Anim. Reprod. Sci. 65:17-31.

Spicer, L. J., W. B. Tucker, and G. D. Adams. 1990. Insulin-like growth factor-I in dairy cows: Relationships among energy balance, body condition, ovarian activity, and estrous behaviour. J. Dairy Sci. 73:929-937.

Spicer, L. J., R. K. Vernon, W. B. Tucker, R. P. Wettemann, J. F. Hogue, and G. D. Adams. 1993. Effects of inert fat on energy balance, plasma concentrations of hormones, and reproduction in dairy cows. J. Dairy Sci. 76:2664-2673.

SPSS. 2002. SPSS for Windows version 11.5. SPSS Inc., Chicago, IL.

StataCorp. 2001. Stata Statistical software:Release 7.0. Stata Corporation, College Station, TX.

Thissen, J. P., J. M. Ketelslegers, and L. E. Underwood. 1994. Nutritional regulation of the insulin-like growth factors. Endocr. Rev. 15:80-101.

Vega, J. R., C. A. Gibson, T. C. Skaar, D. L. Hadsell, and C. R. Baumrucker. 1991. Insulin-like growth factor (IGF)-I and II and IGF-binding proteins in serum and mammary secretions during the dry period and early lactation in dairy cows. J. Anim. Sci. 69:2538-2547.

Yilmaz, A., M. E. Davis, and R. C. M. Simmen. 2004. Estimation of (co) variance components for reproductive traits in Angus beef cattle divergently selected for blood serum IGF-I concentration. J. Anim. Sci. 82:2285-2292.

Zapf, J., C. Hauri, M. Waldvogel, and E. R. Froesch. 1986. Acute metabolic effects and half-lives of intravenously administered insulin-like growth factor I and II in normal and hypophysectomised rats. J. Clin. Invest. 68:1321-1330. 